\title{
Establishment and applications of quality management system for service industries
}

\author{
King-Jang Yang1, Shun-Hsing Chen ${ }^{2 *}$, Ching-Chow Yang ${ }^{3}$ \\ Professor, Center for General Education, National Quemoy University, Taiwan, R.O.C. ${ }^{1}$ \\ Professor, Department of Marketing \& Distribution Management, Oriental Institute of Technology, \\ Taiwan, R.O.C. ${ }^{2 *}$ \\ Professor, Department of Industrial and Systems Engineering, Chung-Yuan University, Taiwan, \\ R.O.C. ${ }^{3}$ \\ kingjang@nqu.edu.tw ${ }^{1}$, chen88@mail.oit.edu.tw ${ }^{2 *}$, yang93235@yahoo.com.tw ${ }^{3}$
}

等

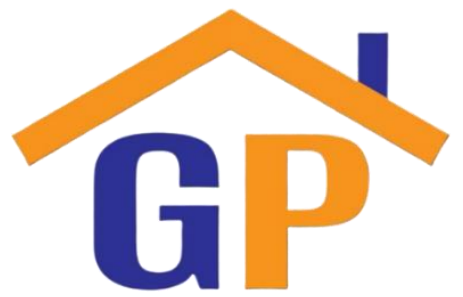

Article History

Received on 1 March 2020

$1^{\text {st }}$ Revision on 10 March 2020

$2^{\text {nd }}$ Revision on 26 March 2020

Accepted on 3 April 2020

\begin{abstract}
Purpose: Because of the limited resources and lack of knowledge and experience related to quality management, the service firms perform very few quality practices only, and result in a very limited effectiveness. This research tried to develop a systematic framework of quality management with several hierarchical constructs for service industries.
\end{abstract}

Research methodology: This study also used Delphi and AHP method to examine the importance and the priorities of the five quality management stages and their involving practice activities, which are the valuable guideline for the service industries to implement the quality management successfully.

Results: It is found that the service enterprises need to first assure the quality in service encounter, then can upgrade the implementation levels to delivery process and management system. But the practices in 'total quality' stage are the fundamental forces of the implementation of quality practices in the initial stages.

Limitations: The AHP experts only comment on this issue not applicable to all industries. The research findings apply only to the service industry.

Contribution: The service enterprises need to perform TQM successfully. After all the previous stages of quality management are performed very well, the service enterprises can raise the implementation level to the business quality.

Keywords: Service industries, Service quality, Hierarchical quality management system, AHP method

How to cite: Yang, K.-J., Chen, S.-H., \& Yang, C.-C. (2020). Establishment and applications of quality management system for service industries. International Journal of Financial, Accounting, and Management, 1(4) 199-207.

\section{Introduction}

In most countries around the world, especially the developed countries, service industries play very critical role in the economic development, the service sectors contribute to huge part of GDP (SohelUz-Zaman \& Anjalin, 2011), they contribute to GDP more than 70\% in developed countries. Even in the developing countries, the service industries also significantly contribute more than $50 \%$ GDP to their country (UNCTAD Handbook of Statistics, 2010). The service industries are also the biggest contributors to the labor employment in many countries (Sohel-Uz-Zaman \& Anjalin, 2011), for examples, in the developed countries USA, UK, Canada, New Zealand, Australia, etc., the service industries contribute to labour employment more than 75\% (Yang, 2009). The number of new jobs created by service industries significantly dominates that created by manufacturing industries across the world, since many new service industries emerged due to the creation of huge amount of new 
services (Sohel-Uz-Zaman \& Anjalin, 2011). In Taiwan, the service industries contribute about 70\% in GDP, and provide about 58\% of total employees (National Statistics, ROC, 2016).

In today service industries encounter more intense competition than manufacturing. Thus the service industries should improve their competitive ability (Yang, 2011). The core competition of service enterprises is determined by their ability to enhance their relationships with their customers by fulfilling their present needs and anticipating their prospective needs and expectations (Gale, 1990; Yang, 2011). In order to sustain the competitive advantage, service companies not only need to devote themselves to retaining existing customers but also to attracting new customers. It means that enhancing the customer loyalty should be the critical concerns of any business (Gorst et al., 1998; Ciavolino et al., 2019; Chen et al., 2020).

Customer loyalty is the result of the customers' perception of service quality and value. It is therefore that there is a strong link between customer loyalty and customer satisfaction (Gorst et al., 1998; Amenta et al., 2019). The popular model 'American Customer Satisfaction Index (ACSI)' (Fornell, 1992; Fornell et al., 1996) specifies this linkage, which identifies three antecedents to loyalty (perceived quality; customer expectation; and perceived value) and two consequences of loyalty (customer loyalty; and customer complaints). The ACSI measures the actual perceived quality (as evaluated by customers) and the resulting level of customer satisfaction (Liu and Ko, 2018; Brentari et al., 2019). Based on the reference of ACSI model, the European Customer Satisfaction Index (ECSI) has also been developed (ECSI Technical Committee, 1998), which is very similar to ACSI.

With respect to the raise of customer satisfaction and hence customer loyalty, the service enterprises should pay more attention on the implementation of quality management. But the service enterprises will encounter some problems while they want to implement some quality activities. For examples:

$>$ The service industries are usually with small scales, most of the service companies have less than 10 employees.

$>$ Their resources are very limited compared to manufacturing industries.

$>$ They are lack of qualified specialist personnel in the quality field.

$>$ Top managements in these service enterprises are result-oriented,

$>$ Their knowledge and experience related to the recent quality management systems, such as TQM, Six Sigma, and Kaizen are very poor (Yang, 2009).

It is therefore that many countries' governments actively promote the quality programs and provide the funds and consultants to help the service industries to adopt some effective quality activities. Recently, Taiwan governments have made efforts to assist the service industries to implement quality management. Usually, the service industries will adopt some quality management systems such as ISO9000, total quality management (TQM), or even the Six-Sigma program. Due to the resistant factors discussed above, they can't successfully implement these quality management systems. Thus, 'how to effectively implement quality management' is a focal issue for service industries. Though there are many researches discussed the implementation of quality management with respect to service industries, scant academic attention reflects the development of quality management system which is suitable for service industries. Actually, it is very needed to develop an appropriate model of quality management system which can be an essential guideline for service enterprises, when they want to adopt the quality management activities.

This study tried to develop a systematic framework of quality management with several hierarchical constructs for service industries based on the literature review and expert interviews, in which there are several practices in each construct. This study then used the Delphi Method to identify the critical constructs and their involving practices. After that, we take the method of Analytical Hierarchy Process (AHP) to examine the importance priorities of the quality management constructs and the quality management practices, which are the valuable guideline for service industries to successfully implement the quality management. The research methods Delphi Method and AHP are both based on the coincidences of experts' opinions and the utilization of the questionnaire. 


\section{Literature review}

\subsection{Service quality model (PZB model)}

Due to the limitations and obstacles described above, it is not appropriate for service enterprises to adopt the quality management programs with complicated system in the initial stage. If a service company starts to implement some quality programs, the best way is first to focus on the customer service and service provision. After the initial programs are well performed, it can extend the quality activities to cover the service delivery process and the management system, and even the total quality aspects. It means that the suitable implementation system of quality management for service enterprises is to be a hierarchical system with different stages (Samani et al., 2019).

How to develop this suitable quality management system? There are several researches can be referred. Caro and Garcia (2008) suggested a framework of service quality evaluation, which is constituted of four constructs and involving total ten evaluation items: personal interaction (including manner, behavior, professional techniques, problem solving), service design (service contents, operation time), physical environment (tangible parts, information), and service outputs (punctuality, effectiveness). The important referred research is the 'conceptual model of service quality' developed by P.Z.B. (Parasuraman et al., 1985). This model consists of five gaps, which are

$>$ Gapl Understanding gap: in the service encounter, the service personals will miss the understanding the customer's needs.

$>$ Gap2 Design gap: the service design may not match the description of customer's needs.

$>$ Gap 3 Service delivery gap: the service delivery sometimes does not follow the service-design specifications and contents.

$>$ Gap 4 Communication gap: the provided service contents may not coincide with the extent communication.

$>$ Gap 5: Expectation-perception gap: the customers' perception of service quality is different from their subjective preferences.

This gaps model is displayed in Figure 1, which demonstrates that the occurrence of these gaps will result in adverse effects on the service quality. Thus the service organizations usually adopt some actions to eliminate these gaps (by the providers) in order to improve service quality (as perceived by customers) (Yang, 2006). The critical referred research is the work of Yang (2006), he developed a quality management system for service industries. This integrated quality management system is constituted of five stages and involving total 25 practices, stated as follows.

> Long-term planning: Core value and commitment of top management, mission and vision, targeted and positioned markets, strategic planning and management, customer focus, quality polices and strategic objectives.

$>$ Short-term planning: Design of service delivery, organization design and adjustment, employee education and training, standardization of operation procedures, analytic information system, empowerment.

> Daily management: Leadership, employee motivation, inputs control, marketing control, control of service design, analyses of daily information, control of service delivery.

$>$ Check management: Customer satisfaction survey, assessment of employee performance, quality audit.

> Improvement actions: Continuous improvement, after service. 


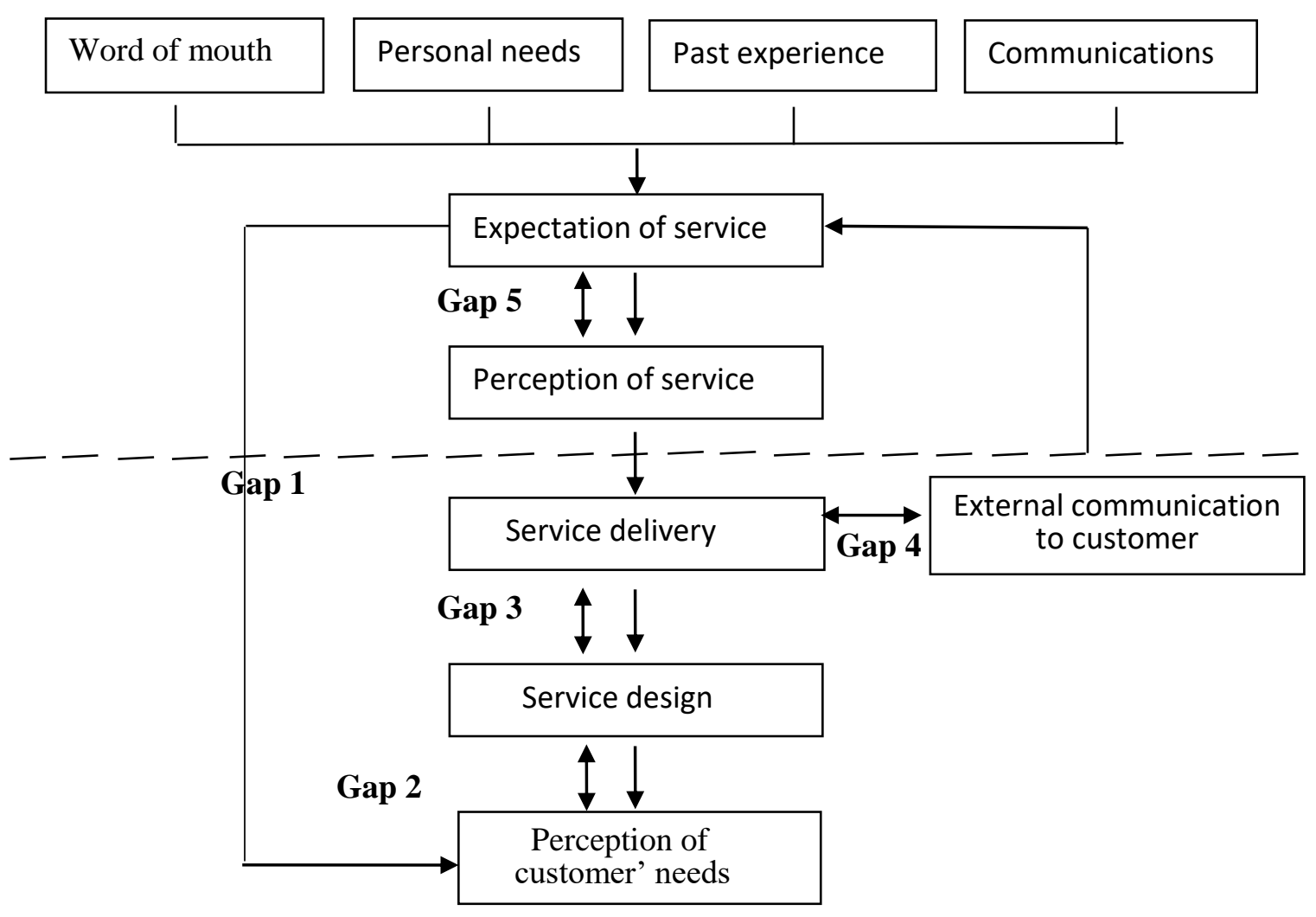

Figure 1. The cconceptual model of service quality developed

Source: Parasuraman et al., (1985)

\subsection{Establishment the hierarchical quality management system}

Besides, there are some studies referred by many researchers such as Fitsimmons \& Fitsimmons (2008) and Yang (2009). This study also interviews with ten experts and high managers of famous service companies in Taiwan. Based on the literature review and expert interviews, this study developed a hierarchical quality management system with different stages for service industries, which is displayed as Figure 2.

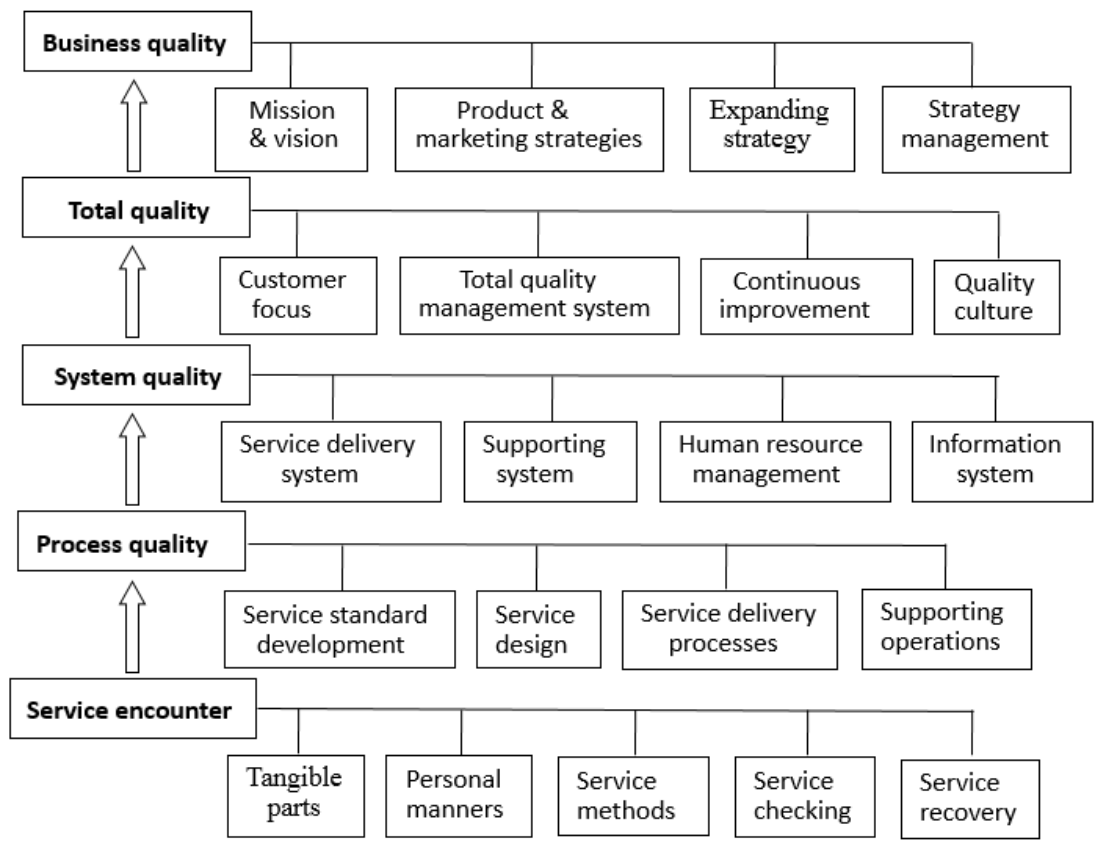

2020 | International Journal of Financial, Accounting, and Management/ Vol 1 No 4, 199-207 
Figure 2. The hierarchical quality management system with five stages for service industries If a service company wants to adopt quality management, but lacks of the experience of the implementation of quality management, it needs to initiate the first stage 'service encounter'. The practices in this stage are the critical factors to affect the customer perception of service quality. After these practices are well performed, this study found there are some quality problems happened, which will be caused in the service delivery processes. It is therefore that the service firm shall raise the implementation level of quality management, which is the stage 'process quality'. The practices in this stage are the fundamental imperatives for the operations of the practices in the first stage. Similarly, as the practices in the previous stages are performed very well, then the service firm can upgrade the implementation stages in the hierarchical quality management system. The realization of total quality management (TQM) (the first four stages) is the prerequisite to successfully perform the business strategies, which is the top stage. The objective of the development of this hierarchical quality management system with five stages is to provide the guideline for the service enterprises to adopt the quality management effectively.

\section{Research methodology}

Though the hierarchical quality management system is developed by using the serious research methods, it is also needed to examine the essentials of the involving practices based on the experts' unanimity. In this research, the Delphi method is used, since it is used to achieve a consensus opinion from a group of participants (usually the experts). The consensus is determined by using the questionnaire with importance statement of the inter-quartile range of each item. The application of Delphi method needs the eligible experts for the participants. The study requested 12 high managers (including chairman of board committee, general manager, vice general managers, president, senior managers) from several leading service companies in Taiwan, two professors with major research of service management, and three consultants in service management.

Usually the Delphi method will be preceded in two stages, and the pre-designed questionnaires are used to do the examination of critical elements in the developed model. In the hierarchical quality management system with five stages (Figure 2), total 21 practices are considered in this developed model. In order to design the questionnaire used in the first stage, this study consider $4 \sim 7$ operation items in each practices, and total 122 question items are considered in the questionnaire. The question items called for responses use a 7-point Likert-type scale, from $1=$ strongly unimportant to $7=$ Strongly important. In the questionnaire survey in the first stage, the questionnaires are sent to the 17 participants, and all the questionnaires were received. After the statistical analyses, if the items are to be with mode $\mathrm{M}_{0} \leq 5$ and mean $\overline{\mathrm{x}}<5.5$, then these items would belong to lowly important (Uhl, 1990) and can be deleted.

The 17 participants received interview are asked to address their judgments regarding the term evaluation of the operation items in the hierarchical service quality system. After analyzing the results of the first round, the words and question content were reformed. One question was eliminated which is in the practice 'expanding strategy' with $\mathrm{M}_{0} \leq 5$ and mean $\overline{\mathrm{x}}<5.5$, but one new question was added according to the participants' suggestions. The revised questionnaire is used for the second round of Delphi method, and the final questionnaires were sent to the same participants for reviewing the items; the percentage of the returned completed questionnaires in the second round is $100 \%$. In the statistical analyses, all the questions are to be with $\mathrm{M}_{0}>5$, and $\overline{\mathrm{x}} \geqq 5.5, \sigma \leqq 1.0$. The results show that operation items and therefore the practices are very essential in the developed hierarchical quality management system with five stages for service industries.

In order to examine the priorities of the five stages and their involving practices, the AHP method was used. AHP is a systematic methodology to collect valuable information, in which judgments and measurements from the experts are to be included and integrated (Saaty, 1980; Saaty et al., 2003). AHP is also a decision making model, which consists of three part process; identifying and organizing the decision objectives or alternatives into a hierarchy, assessing the pair-wise comparisons between the relevant elements at each level of the hierarchy, and using the mathematical algorithm to evaluate the priorities of the elements in all the levels (Saaty, 1990).

$$
2020 \text { | International Journal of Financial, Accounting, and Management/ Vol } 1 \text { No 4, 199-207 }
$$


The study first organized a structure with three hierarchies of the objectives based on the developed model (Figure 2) and the analytic results of the application of Delphi method. Since the operation items considered in Delphi method are too many, the study first delete some items with $\mathrm{M}_{0} \leqq 5$ or $\overline{\mathrm{x}}<5.5$ or $\sigma>1.0$ in the first stage of the Delphi method processing (see Table 1), and then re-organize the relevant items into 54 elements in the third level. Based on this revised quality management system, this study designed the AHP questionnaire with pair-wise comparison form. The study also request the original 17 participants to attend the AHP survey again. There are 15 participants accept our request. All the 15 participants completed the questionnaire.

Table 1. The analytic results of the first stage of the Delphi method

\begin{tabular}{|c|c|c|c|c|}
\hline Stage & Practice & $\mathrm{M}_{0}$ & $\overline{\mathrm{x}}$ & $\Sigma$ \\
\hline \multirow{5}{*}{$\begin{array}{c}\text { Service } \\
\text { encounter }\end{array}$} & Tangible parts & 7 & 6.09 & 0.87 \\
\hline & Personal manners & 7 & 6.27 & 0.80 \\
\hline & Service methods & 7 & 6.10 & 0.90 \\
\hline & Service checking & 6.5 & 6.10 & 0.83 \\
\hline & Service recovery & 7 & 6.34 & 0.62 \\
\hline \multirow{4}{*}{$\begin{array}{l}\text { Process } \\
\text { quality }\end{array}$} & Service standard development & 7 & 6.38 & 0.60 \\
\hline & Service design & 7 & 6.27 & 0.78 \\
\hline & Service delivery processes & 6 & 5.95 & 0.80 \\
\hline & Supporting operations & 6 & 6.24 & 0.68 \\
\hline \multirow{4}{*}{$\begin{array}{l}\text { System } \\
\text { quality }\end{array}$} & Service delivery system & 6 & 5.91 & 0.83 \\
\hline & Supporting system & 6 & 6.07 & 0.82 \\
\hline & HRM & 7 & 6.20 & 0.82 \\
\hline & Information system & 7 & 6.42 & 0.80 \\
\hline \multirow{4}{*}{$\begin{array}{l}\text { Total } \\
\text { quality }\end{array}$} & Customer focus & 7 & 6.32 & 0.68 \\
\hline & TQM system & 7 & 6.10 & 0.84 \\
\hline & Continuous improvement & 6 & 6.08 & 0.78 \\
\hline & Quality culture & 7 & 6.42 & 0.68 \\
\hline \multirow{4}{*}{$\begin{array}{c}\text { Business } \\
\text { quality }\end{array}$} & Mission \& vision & 7 & 6.37 & 0.77 \\
\hline & Product \& marketing strategies & 7 & 6.18 & 0.82 \\
\hline & Expanding strategy & 6 & 5.80 & 1.26 \\
\hline & Strategy management & 6.5 & 6.21 & 0.69 \\
\hline
\end{tabular}

The consistency of the experts' assessments is very critical for the application of AHP model. The 'consistency ratio' (C.R.), which is depends on the 'consistency index' (C.I.), is a useful mechanism for evaluating the consistency of the decision making by AHP survey (Saaty, 1990). Saaty (1990) asserted that if C.R. $\leq 0.1$, then the consistency of the AHP results is approved. In this research this 
study use the soft system Expert Choice 2000 to conduct the analyses. This study obtain that C.R. $<0.1$, and the AHP results can be accepted.

\section{Results and discussions}

\subsection{Empirical analysis}

In this section discussed the importance priorities of the quality management stages and their involving quality practices, as shown in Figure 2. The analytic results of priority ranking and their related weights obtained from the AHP survey for the five quality management stages are listed in Table 2. This study also list the priority ranking of all the 17 quality management practices within their related stage and in the total system, see Table 3.

Table 2. The priority ranking of the five stages

\begin{tabular}{|l|c|c|c|c|c|}
\hline $\begin{array}{c}\text { Quality management } \\
\text { stage }\end{array}$ & $\begin{array}{c}\text { Service } \\
\text { encounter }\end{array}$ & $\begin{array}{c}\text { Process } \\
\text { quality }\end{array}$ & $\begin{array}{c}\text { System } \\
\text { quality }\end{array}$ & $\begin{array}{c}\text { Total } \\
\text { quality }\end{array}$ & $\begin{array}{c}\text { Business } \\
\text { quality }\end{array}$ \\
\hline Weight & 0.151 & 0.138 & 0.124 & 0.294 & 0.293 \\
\hline Priority & 3 & 4 & 5 & 1 & 2 \\
\hline
\end{tabular}

Table 3: The priority ranking of the quality management practices

\begin{tabular}{|c|l|c|c|c|c|}
\hline Stage & Practice & \multicolumn{2}{|c|}{ Priority within stage } & \multicolumn{2}{c|}{ Priority in total system } \\
\cline { 2 - 6 } & & Weight & Priority & Weight & Priority \\
\hline \multirow{3}{*}{$\begin{array}{c}\text { Service } \\
\text { encounter }\end{array}$} & Tangible parts & 0.152 & 4 & 0.022 & 18 \\
\cline { 2 - 6 } & Personal manners & 0.362 & 1 & 0.052 & 7 \\
\cline { 2 - 6 } & Service methods & 0.194 & 2 & 0.027 & 14 \\
\cline { 2 - 6 } & Service checking & 0.157 & 3 & 0.022 & 16 \\
\cline { 2 - 6 } & Service recovery & 0.135 & 5 & 0.019 & 20 \\
\hline \multirow{3}{*}{$\begin{array}{c}\text { Process } \\
\text { quality }\end{array}$} & Service standard development & 0.289 & 1 & 0.034 & 9 \\
\cline { 2 - 6 } & Service design & 0.283 & 3 & 0.033 & 11 \\
\cline { 2 - 6 } & Service delivery processes & 0.286 & 2 & 0.033 & 10 \\
\cline { 2 - 6 } & Supporting operations & 0.142 & 4 & 0.016 & 21 \\
\hline \multirow{3}{*}{$\begin{array}{c}\text { System } \\
\text { quality }\end{array}$} & Service delivery system & 0.309 & 2 & 0.051 & 8 \\
\cline { 2 - 6 } & Supporting system & 0.123 & 4 & 0.020 & 19 \\
\cline { 2 - 6 } & HRM & 0.432 & 1 & 0.071 & 6 \\
\cline { 2 - 6 } & Information system & 0.136 & 3 & 0.022 & 17 \\
\hline \multirow{2}{*}{$\begin{array}{c}\text { Total } \\
\text { quality }\end{array}$} & Customer focus & 0.342 & 2 & 0.096 & 3 \\
\cline { 2 - 6 } & TQM system & 0.094 & 4 & 0.027 & 15 \\
\cline { 2 - 6 } & Continuous improvement & 0.115 & 3 & 0.031 & 12 \\
\cline { 2 - 6 } & Quality culture & 0.449 & 1 & 0.127 & 1 \\
\hline \multirow{2}{*}{$\begin{array}{c}\text { Business } \\
\text { quality }\end{array}$} & Mission \& vision & 0.269 & 3 & 0.079 & 5 \\
\cline { 2 - 6 } & Product \& marketing strategies & 0.293 & 2 & 0.087 & 4 \\
\cline { 2 - 6 } & Expanding strategy & 0.097 & 4 & 0.029 & 13 \\
\cline { 2 - 6 } & Strategy management & 0.341 & 1 & 0.101 & 2 \\
\hline
\end{tabular}

The results are very interesting. Usually the service industries, especially the small enterprises, will pay more attention on the practices of the 'service encounter' stage, but the priority of this stage is only ranking 3 , not the top priority. The top one priority is the stage 'total quality', due to its practices 'quality culture' and 'customer focus' which are ranking top one and third respectively in the total system, especially the practice 'quality culture' which weight is very high. Actually 'quality culture' and 'customer focus' are the fundamental drivers of the other quality management practices. The practices in stage 'service encounter' are deeply influenced by these two practices. There is a surprise finding which is that the ranking of the stage 'business quality' is top two, in which there are three practices 'strategy management', 'product and marketing strategies' and 'mission and vision' which 
are ranking in top five (their rankings are 2, 4, and 5 respectively), see Table 3 . It can be explained that the strategies of product and marketing, and the implementation of these strategies will affect the development of 'service standard', 'service design', 'service delivery processes', and 'service delivery system', etc.

\subsection{Discussion}

It is needed to emphasize that the practices 'human resource management' (in stage 'system quality'), and 'personal manners' (in stage 'process quality') are also important, which rankings are 6 and 7 of the total system respectively. This finding provides the evidence that service personal is the critical factor of the service quality. Though the ranking of the stage 'process quality' is priority 4 , but there are three practices 'service standard development', 'service delivery processes', and 'service design' in this stage are moderately important, which rankings are 9, 10, and 11 respectively. The ranking of stage 'system quality' is the last one, but its practices 'human resource management' and 'service delivery system' are very critical for the pursuit of service quality.

Based on the results of the Delphi study, all the 21 quality management practices are the critical factors of pursuing the good service quality. Thus the service enterprises don't neglect the practices which rankings are listed in the last items, for examples, 'supporting operations', 'service recovery' and 'supporting system'. The supporting system and the involving processes are the critical factors of the service delivery, and the 'service recovery' is much needed as the failure of the service delivery happened.

\section{Conclusion}

If the service enterprises want to adopt and implement the quality management, they will start the basic quality practices, which are including in the stage 'service encounter'. Gradually, they will discover that only implementing the basic practices is not enough for pursuing good service quality, it is needed to extend the extent of the quality management. They should upgrade the stage 'process quality', and even the stage 'system quality'. But the realization of the quality management practices in these three stages is very difficult, unless the service firms effectively implement the total quality management (TQM) activities. The analytic results of the AHP study in this research shows that the practices in 'total quality' stage are the critical drivers of the effective implementation of the practices in the first three stages.

Some practices in the stage 'business quality' will determine the development of service processes and service system, and affect the decision of the service methods, personal manners, and service standards. Thus, if the service enterprises intend to pursue customer loyalty and the excellent business performance, they must successfully implement the 'business quality'. It can be concluded that in the initial stage of implementing the quality management, they should adopt the basic quality practices, and then extend to the process and system levels.

This study used AHP research method to study the importance priority for the five stages of quality management, and the practices in these stages. The stage 'total quality' is top one. It means that only performing the TQM activities can assure the realization of the quality practices in the initial stages. In order to pursue the excellent business performance, they need to successfully implement the practices in the 'business quality' stage.

\section{References}

Amenta, P., Lucadamo, A., \& D'Ambra, A. (2019). Customer satisfaction evaluation by common component and specific weight analysis using a mixed coding system. Quality \& Quantity, 53(5), 2491-2505.

Brentari, E., Battista, T. D., Crocetta, C., \& Simonetti, B. (2019). New challenges for services quality evaluation. Quality \& Quantity, 53(5), 2273-2273.

Caro, L. M., \& Garcia, J. A. M. (2008). Developing a multidimensional and hierarchical service quality model for the travel agency industry. Tourism Management, 29(4), 706-720. 
Ciavolino, E., Salvatore, S., Mossi, P., \& Lagetto, G. (2019). High-order PLS path model for multigroup analysis: the prosumership service quality model. Quality \& Quantity, 53(5), 2371-2384.

Chen, S. H., Pai, F. Y., \& Yeh, T. M. (2020). Using the Importance-Satisfaction Model and Service Quality Performance Matrix to Improve the Long-Term Care Service Quality in Taiwan. Applied Sciences, 10(1), 1-16.

ECSI Technical Committee (1998). European Customer Satisfaction Index Foundation and Structure for Harmonized National Pilot Projects, ECSI.

Fitzsimmons, J. A., \& Fitzsimmons, M. J. (2008). Service Management: Operations, Strategy, and Information Technology, 6th Edition. NY: McGraw-Hill.

Fornell, C. (1992). A national customer satisfaction barometer: The Swedish experience. Journal of Marketing, 56(1), 6-21.

Fornell, C., Ittner, Christopher D., \& Larcker, D. F. (1996). The evaluation consequences of customer satisfaction. National Quality Research Center, Working Paper, National Quality Research Center, Ann Arbor, MI.

Gale, T. B. (1990). The role of marketing in total quality management. In: QUIS-2 Quality in Services Conference Proceedings, University of St. John's. Minnesota, 5 November, 1990.

Gorst, J., Kanji, G., and Wallage, W. (1998). Providing customer satisfaction. Total Quality Management, 9(4\&5), 100-103.

Liu, Y.L., \& Ko, P.F. (2018). A modified EFQM Excellence Model for effective evaluation in the hotel industry. Total Quality Management \& Business Excellence, 29(13-14), 1580-1593.

National Statistics, ROC. (2016). The Statistics of GDP and Employment of Service Sector in Taiwan. Directorate-General of Budget, Accounting and Statistics, Executive Yuan, ROC (Taiwan).

Parasuraman, A., Zeithaml, Valarie A., \& Berry, L. L. (1985). A conceptual model of service quality and its implications for future research. Journal of Marketing, 49(3), 41-50.

Saaty, T. L. (1980). The Analytic Hierarchy Process. New York: Mac Gray-Hill.

Saaty, T. L. (1990). How to make a decision: The analytic hierarchy process. European Journal of Operational Research, 48(1), 9-26.

Saaty, T. L., Vargas, L. G., \& Dellmann, K. (2003). The allocation of intangible resources: The analytic hierarchy process and linear programming. Socio-Economic Planning Sciences, 37(3), 169-184.

Samani, M.A., Ismail, N., Leman, Z., \& Zulkifli, N. (2019). Development of a conceptual model for risk-based quality management system. Total Quality Management \& Business Excellence, 30(56), 483-498.

Sohel-Uz-Zaman, A. S. M., \& Anjalin, U. (2011). Evolution of service: Importance, competitiveness and sustainability in the new circumstances. Journal of Service Science and Management, 4, 253 260.

Uhl, N. P. (1990). Evaluation model and approaches-Delphi technique, in Walberg, H. J., \& Haertal, B., The International Encyclopedia of Education. Oxford, Pergamon.

UNCTAD Handbook of Statistics (2010). United Nations Conference on Trade and Development, United Nations publication, Geneva.

Yang, C.C. (2006). Establishment of a quality-management system for service industries. Total Quality Management \& Business Excellence, 17(9), 1129-1154.

Yang, C.C. (2009). Service Quality. Hwa Tai Publishing, Taipei.

Yang, C.C. (2011). The identification of customer delight for quality attributes and its applications. Total Quality Management \& Business Excellence, 22(1-2), 83-98. 